\title{
ARTICLE \\ Droughts and the Impacts of Dry Spells in North of Iraq
}

\author{
Safieh Javadinejad $^{1 *}$ David Hannah $^{1}$ Stefan Krause $^{1}$ Rebwar Dara $^{2}$ Forough Jafary ${ }^{1}$ \\ Mohsen Nasseri ${ }^{3}$
}

1.University of Birmingham, Birmingham, UK

2.University of knowledge, Erbil, Iraq

3.University of Tehran, Tehran, Iran

\section{ARTICLE INFO}

Article history

Received: 29 January 2021

Accepted: 15 March 2021

Published Online: 30 March 2021

\section{Keywords:}

Dry spells

Drought

Climate change

Indices

\begin{abstract}
Different sets of dry spell length such as complete series, monthly maximum, seasonal maximum, and annual maximum are applied and modeled with different probability distribution functions (such as Gumbel Max, generalized extreme value, Log-Logistic, generalized logistic, inverse Gaussian, Log-Pearson 3, generalized Pareto) to recognize in which duration, dry spells cause drought. The drought situation and temporal analysis in the North of Iraq region were done using the SPI index and by software of DrinC at a time scale of 3.6 and 12 months. Because of applicability, availability of data and the aim of the study, SPI is selected to analyze the dry spells in this study. Based on the maximum length of the available statistical period, the statistics for the years 1980 to 2019 were used from nine meteorological stations for analysis. The results of the study showed the severity of drought during the study period which related to dry spells. The results of this research confirm the variation of drought occurrence with varying degrees in different time and different dry spells condition in Iraq.
\end{abstract}

\section{Introduction}

Drought is one of the most disastrous natural disasters and it is known as continuous and abnormal shortage of precipitation and humidity which have a gradual effect and occurs over a long period of time ${ }^{[1],[2],[3],[4]}$. Therefore, prediction and readiness to manage it, to some extent, reduce the problems caused by this phenomenon ${ }^{[5]}$, $[6],[7],[8],[9],[10]$. Currently, drought management in many arid and semi-arid regions is based on crisis management, and because planning has not been finalized, decisions and operational actions are late, and decisions are lacking in efficiency ${ }^{[11],[12],[13],[14]}$. However, in managing drought crisis, emphasis on planning and preparation and reduction of drought crisis, and with the application of this kind of management at the time of drought and drought preparedness can be done to counteract the drought ${ }^{[15],[16],[17]}$. This phenomenon can occur in each region with varying intensity and continuity, and can affect the human and the environment ${ }^{[18],[19]}$. Therefore, droughts in recent years in most dry and semi-arid countries have led to a sharp drop in groundwater aquifers and a decrease in surface water resources, and eventually a large population of the country faces a depression crisis ${ }^{[20],[21]}$. Droughts are mainly due

*Corresponding Author:

Safieh Javadinejad,

University of Birmingham, Birmingham, UK;

Email: javadinejad.saf@ut.ac.ir 
to precipitation, but the occurrence of successive droughts due to serious changes in dry spells, intensity, period and spatial-temporal distribution of the precipitation ${ }^{[22]}$. Creating such changes will result in meteorological, agricultural, hydrological and socioeconomic droughts. Since the definition, detection, and measurement of complex droughts are complex, researchers have sought to elaborate indicators to determine these ${ }^{[23]}$. The purpose of the preparation and application of any drought index is to determine the characteristics of dry spells, intensity, continuity and spatial extent. In order to monitor the drought situation, several indicators are presented in different countries based on drought definitions and computational method, one of the indicators used in this research is the standardized rainfall index (SPI). The aim of this study is to analyze characteristics of dry spells by using SPI in the north of Iraq. So far there are many indicators for drought monitoring, but some of them are more usable due to their ease of use and applicability. For example, the Standardized Precipitation Index (SPI) for monitoring meteorological droughts has been calculated for different dry spells and is important for initial alert detection and evaluation of drought severity ${ }^{[24]}$. Here in below, the most common methods are explained, however considering the objective of this research and availability of data, the SPI method finally is selected for analyzing the dry spells.

\section{Comparison Different Methods}

The sequencing of dry and wet spells is of great importance in water resource management studies, especially in arid and semi -arid regions. Due to the complexity of hydro-climatic phenomena, it is more difficult to understand the phenomena compare to other natural habitats, and more information is needed to manage the problems and problems of water resources due to the occurrence of dry spells in a region. One of the applications for determining wet and dry spells is water production and cultivar planning, a brief description of drought, flood formation, and forecasting and assessing the occurrence of floods. Also, the possibility of accurately calculating the evaporation rate, determining the relationship between rainfall and rainfall, controlling surface currents, surface water and underground water management studies are among the issues that emphasize the importance of wet and dry spells. Therefore, the determination of degree, intensity, time of occurrence and termination of dry spells is very difficult and requires tools for monitoring and evaluation. In this regard, the use of indicators is due to their ease of use, including methods for determining dry and wet spells. It is also possible to provide meteorological, hydrological and agricultural purposes for calculating indices at differ- ent time scales. However, in the analysis of dry and wet spells, factors such as rainfall, temperature, runoff, soil moisture, evapotranspiration and wind should be considered, but in the meantime, the rainfall factor due to direct and indirect effects on other parameters, is more important. Precipitation is the most important factor in determining the beginning, severity and termination of dry and wet periods ${ }^{[25]}$.

The definition of dry spells based on the length of days without precipitation has been widely used in many climatological studies. The advantage of using these definitions and similar definitions is one in determining the thresholds and the other in facilitating the use of specific statistical analyzes for studying dry spells with different continuations ${ }^{[26],[27],[28],[29]}$. Several methods have been used to study the behavior of wet and dry spells. Here in below, different methods are explained:

\subsection{Standardized Rainfall Index}

The basis of the standard rainfall index is based on the calculation of precipitation probabilities for each time scale. After extraction of rainfall data on a monthly scale during a statistical period, it is necessary to create a total time series of rainfall on an arbitrary scale. This profile is based on rainfall data, and its variability makes it possible to use a short-term scale for agricultural purposes and in long-term qualifications for aquatic objectives such as groundwater resources, river flows, lakes and surface resources. In this study, in order to calculate the drought by the standardized precipitation index, monthly rainfall data of 9 barometric stations were used and made by DrinC software. This software is designed to determine drought indices and it is possible to use the annual, monthly, seasonal, moving and daily data series. In this study, after gathering the precipitation data of the stations in the area and removing the stations with incomplete statistics, during the common statistical period of 1980 to 2019 , rainfall data was arranged monthly and using the DrinC software, the SPI time series were scaled for 3, 6 and 12 months, and the values were calculated. Based on Table S1 (Different drought and drought classes in this index), using the values obtained from SPI between 2 and $+2,-2$ or less, $2+$ or more, periods of drought and the severity of drought was obtained in the classes of normal, mild, moderate, severe and very severe.

In this method, the drought period begins when the SPI is continuously negative to reach 1 or less, and ends when the SPI is positive. In addition, the cumulative amounts of SPI also show the magnitude and severity of the drought period. The positive SPI value represents the precipitation over the average rainfall and the negative 
value is the opposite. Therefore, the standard SPI index is suitable for dry and humid climates, and it is possible to compare results in different time periods and locations. In the following, maximum and minimum maximum and minimum values of SPI in the 3,6, and 12-month scales in the statistical period of the study are presented in Table 3 and 4, respectively. Finally, the results have been discussed. Also, spatial distribution of drought condition based on 12-month SPI in a number of study years is provided alternately in Table 2 . At this stage, after calculating the values of the SPI index, the most important features of dry and wet periods, including the total number of dry and wet months, in different classes of drought indicate that the results are presented in Table 3 to 5 .

\subsection{Markov Chain}

Markov's method uses only the two-part values of the existence or absence of daily rainfall, not their quantitative values, with the thresholds set. After collecting data and setting up a database, determining the thresholds for determining the rainy days from the non-operational days was the first phase of the work. There is a great deal of disagreement about the threshold between water and meteorologists, so that they have proposed different criteria for this purpose (various criteria such as $0.1,0.15,0.2$, 0.25 , and 0.3 ). The World Meteorological Organization also defined rainy days with at least $1 \mathrm{~mm}$ of precipitation in 24 hours. However, the use of 10-millimeter reefs has the advantage of removing excess weight, which some very prevalent days end up with a very low frequency at the end of a long dry season, without actually ending the drought. Based on the thresholds, the following indicators for all stations should be extracted.

1. Percentage of dry days during the year with three thresholds of $0.1,1,10 \mathrm{~mm}$ for each station separately;

2. The length of dry periods with three thresholds of 0.1 , $1,10 \mathrm{~mm}$ for each station separately;

3. Maximum duration of dry periods with three thresholds of $0.1,1,10 \mathrm{~mm}$ for each station separately;

4. Extraction of the longest dry period during each study period for each station separately;

5. Extracting the number of dry periods with a duration of 7 days and more, 15 days and more, 30 days and more, 60 days and more, 90 days and more, 120 days and more for each station separately. In order to model the length of dry periods, different order Markov chains, up to the tenth, can use to determine the duration of dry periods, taking into account the threshold (for example, $0.1 \geq$ ) for the definition of precipitation days. Also, the compatibility of each of the different order of the Markov chain on the length of dry periods of stations can be investigated by $(\chi$
2) test.

\subsection{Dry Days Since Last Rain}

The main parameters that should be considered in this method are listed below;

History of precipitation analysis: This date is defined as the basis for the beginning of a new rainfall season, and all rainfall parameters are calculated as DDSLR index relative to this date. Daily Precipitation Limits: The choice of daily precipitation threshold varies according to the purposes and methods used. The common threshold is usually $0.1 \mathrm{~mm}$, which is the minimum accuracy of the rain gauge, which is not desirable for index analysis because of the apparent discrepancy between stations. Therefore, the threshold of daily precipitation is as follows in Equation (1): in this method, first, the ratio of the average total precipitation between the two thresholds of 1 and $0.1 \mathrm{~mm}$ is calculated for the stations, and then, based on the highest percentage obtained, between the stations, the desired threshold determined.

Ratio $=\left(\frac{\text { total }(01)-\operatorname{total}(1)}{\operatorname{total}(01)} \times 100\right)-1$

Equation (1)

Indicator calculation: Indicator is defined by the number of days without precipitation or by precipitation less than a certain threshold from the last rainy day and calculated as follows.

a)Determine zero (0) value: For all berths equal to or greater than the desired threshold;

b)Determine the value of two or three $(1,2,3, \ldots)$ : For all days without precipitation or less than the desired threshold, respectively, from the last rainy day, respectively;

c)This way all years of a statistical period are valued. The first day and every year, if it is rainy, is zero and if it is dry, the continuation of the value of the last day of the previous year is for that purpose.

d)Descending rank: The values obtained for the DDSLR index for each day of the year during the course and calculating its probability are obtained from the following relation.

$\mathrm{P}=\mathrm{m} / \mathrm{n}+1$

Where $p$ is probability and $m$ is mean of DDSLR index for each day of the year and $n$ is the number of the years.

\subsection{ZSI Index}

The following equation can be used to compute the ZSI index:

$\mathrm{Z}=\mathrm{xi}-\mathrm{x}^{-} / \mathrm{s}$

Equation (2)

In the equation, $\mathrm{Z}$ is Standard precipitation score and $\mathrm{xi}$ 
is the average monthly precipitation and $\mathrm{x}$ is the average precipitation for the whole period. Also $\mathrm{s}$ is standard deviation from rainfall is at any time scale. In the Table S2, the severity of the degree of drought is shown based on ZSI values.

\subsection{Nitzche}

Nietzsche by using the annual rainfall data, described the following equation for the study of dry, wet and normal years.

$$
\begin{aligned}
& \mathrm{Pi}>=\overline{(P}+\mathrm{SD}) \\
& \overline{(P}-\mathrm{SD})<=\mathrm{Pi}<=\overline{(P}+\mathrm{SD}) \\
& \mathrm{Pi}<=\overline{(P}-\mathrm{SD})
\end{aligned}
$$

The first equation can use to estimate wet years and the second one can use to estimate normal years and the last one can apply to estimate dry years. Also, Pi showed the precipitation in a given year and $\mathrm{P}$ is the average of precipitation for periods of years and SD is the standard deviation.

The computation of SPI requires that fit is the most appropriate probabilistic distribution function, usually fitted with gamma distributions. Then the cumulative distribution function of the calculated distribution is converted to normal distribution. Among the signs of drought, a significant decrease in rainfall, soil moisture, plant growth and growth can be noted. The onset of drought is usually associated with a decrease in rainfall and increase in dry spells which is known as the meteorological drought. However, over the past century, the world's population has tripled, but water use has increased six-fold. Several studies have been carried out in the world and examples of which are presented here. ${ }^{[30]}$ examined the spatial distribution and severity of drought in South Africa using the SPI index with dry spells in 3, 6 and 12 months. Their results showed that this index is an appropriate tool for monitoring the spatial extension and severity of drought in South Africa. ${ }^{[31]}$ in their study, investigated the effects of climate change on the severity of drought in the great region of Greece, and used data from 50 meteorological stations during the statistical period of 30 years (19601960 ) and found that in all parts of the area there is also a climatic difference. In different periods of time (according to the SPI index), the increase in drought severity has occurred. ${ }^{[32]}$ did a research on the severity, continuity and frequency of climate droughts in six basins in the west and northwest of the country using time series of standardized precipitation index (SPI). For all stations, the severity of drought in each basin was extracted and concluded that the occurrence of drought with dry spells of 1 to 3 month survival, even in stations located in semi-hu- mid areas, is a common and probable phenomenon. ${ }^{[33]}$ studied the drought related to Azarbaijan watershed with the help of standardized rainfall index. They used several stations with a common length of 28 years (1999 - 1972) to monitor droughts in three, six, and 12-month periods, and mapped the extent of the occurrence of droughts. In their findings, the researchers found that there were severe and severe droughts during the statistical period in the region. The lowest SPI observed in the area related to one station on a scale12-month-old with a value of -4.2 and therefore the region was introduced as one of the regions with potential for drought susceptibility in the region. ${ }^{[34]}$, by studying the drought trend in Sistan plain, showed that from 1980 to 2013 the frequency of dry spells and drought occurrence at the Zabol representative station was higher than the 2000-1990 decade, and this station during recent years have been more normal or wet. ${ }^{[35]}$ using standardized precipitation index and Kriging method to investigate drought conditions in the Middle East. This study showed that 8 years of medium to weak drought occurred in the study area and in 2013 the most widespread drought occurred. ${ }^{[36]}$ in his research on the status of drought in Morocco using the standard rainfall index (SPI) as the selected index for monitoring of droughts in stations within the province with a combined statistical period of 25 years (1975-2011) and with considered dry spells for 6, 9, 12 and 24 months were used. The highest dry spells and drought severity was observed in the 6-month period of a station and at 9, 12, and 24 months are related to another Station. SPI values were categorized in the years of severe drought in time scales using geo-statistical techniques on the area of the province. Investigating the maps showed that the extent of drought decreases with increasing time scale and the situation of droughts decreases in the area from west to east. ${ }^{[37]}$ studied the drought monitoring in China using the SPI standard rainfall index in recent years. Then, the standard rainfall index was calculated for the selected stations, and the mapping was done by the IDW method for the area and investigating dry spells for 3, 6, 9, 12, 24 and 84 months. The results showed that drought maps with time series, moderate and severe droughts, have been continuously and successively implemented in recent years in the area, which is the end of the drought period and, more importantly, the consequences of it, up to years after the occurrence of drought, the region will be clear. Therefore, risk management and a serious crisis in relation to this phenomenon are necessary in terms of regional planning and prioritization for specific plans of each region. Also, other studies such as ${ }^{[38],[39]}$ have done drought analysis and evaluation have been conducted based on the SPI index. The prerequisite for the planning 
and management of water resources is the assessment of wet and dry spells that require understanding and studying the occurrence of droughts. The shortage of drinking water due to the degradation of groundwater quality and the reduction of aquifers also lead to widespread immigration. All these make the drought more prudent and more manageable. The dry spells and drought threatens agricultural activities. In addition, performance and product quality are also affected. Due to the damage caused by the dry spells, drought occurrence and considering the studies done in this field, more studies on drought are still needed in different parts of the country. Extreme rainfall is not always the cause of the wet spells. Other factors such as average temperature and relative humidity also affect dry spells and drought aggravated or moderated, and given the fact that the scope of climate research, such as the production of climate maps, can be large, moderate, Small and local, which is very limited in some arid and semi-arid regions. As a result, the SPI index has the most important advantage in terms of drought calculation in different dry spells in terms of severity in arid and semi-arid regions. Drought with other meteorological phenomena varies from meteorological point of view. Often the beginning and end of the drought are important, and its continuity can be relatively long that depends on dry spells. The frequency of dry spells varies in different regions, which is characterized by a large variety of climates. The SPI indicator, as one of the meteorological drought indicators, is able to estimates drought with considering dry spells and it can use for analysis of past droughts and the study of the return periods of droughts to predict the future in each region. SPI index due to its simplicity, and without dimension and it's able to calculate the severity and duration of drought and stress, for the study of droughts and spatial problems in this case study was selected. The purpose of this study was to analyze the temporal of drought severity and duration in Iraq and to use DrinC software capabilities in estimating the standardized rainfall index.

\section{Study Area}

Iraq has a hot, dry climate and known by long, hot, dry summers and short, cool winters. The climate is influenced by Iraq's location between the subtropical aridity of the Arabian desert regions and the subtropical humidity of the Gulf. The coldest month, with temperatures from $5^{\circ} \mathrm{C}$ to $10^{\circ} \mathrm{C}$ is January, and August is the hottest month with temperatures increasing up to $30^{\circ} \mathrm{C}$ and more.

In most of the areas, summers are very hot with the highest sunshine, but there is high humidity on the southern coastal areas of the Gulf. Daily temperatures can reach easily $45^{\circ} \mathrm{C}$ or more during summer, especially in the Iraqi desert areas which causes a danger of heat exhaustion. Inside the hot, dry desert, the winds can be very strong sometimes, and can cause violent sandstorms. About 70 percent of the average rainfall in the country falls between November and March, but from June to August are often rainless. Rainfall changes from season to season and from year to year. The locations of the synoptic stations are shown in the Figure 1 and the data that used for this research are from the year of 1980 to 2019 .

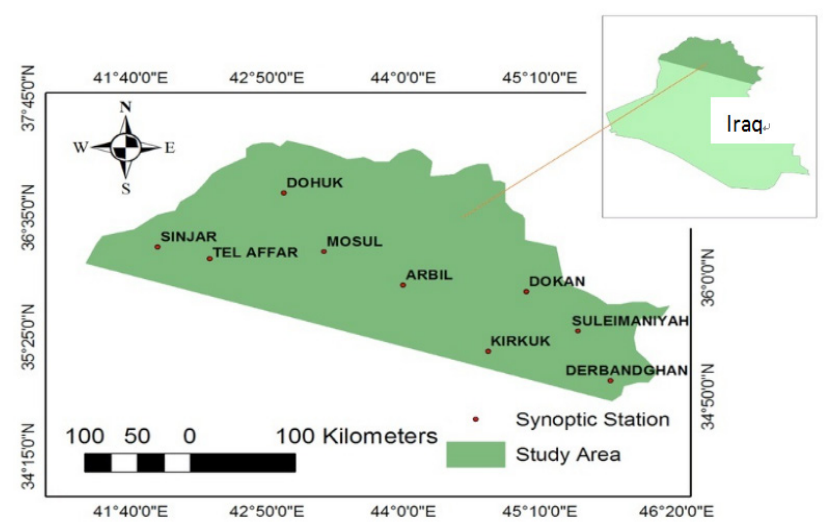

Figure 1. The location of study area and meteorological stations (synoptic stations).

\section{Material and Methods}

\subsection{Standardized Rainfall Index}

The basis of the standard rainfall index is based on the calculation of precipitation probabilities for each time scale. After extraction of rainfall data on a monthly scale during a statistical period, it is necessary to create a total time series of rainfall on an arbitrary scale. This profile is based on rainfall data, and its variability makes it possible to use a short-term scale for agricultural purposes and in long-term qualifications for aquatic objectives such as groundwater resources, river flows, lakes and surface resources. In this study, in order to calculate the drought by the standardized precipitation index, monthly rainfall data of 9 barometric stations (Dohuk, Sinjar, Tel affar, Mosul, Arbil, Kirkuk, Suleimaniyah, Derbandghan, Dokan) were used from the year of 1980 to 2019 (Agha et al. 2017) and made by DrinC software. This software is designed to determine drought indices and it is possible to use the annual, monthly, seasonal, moving and daily data series. In this study, after gathering the precipitation data of the stations in the area and removing the stations with incomplete statistics, during the common statistical period of 2000 to 2014, rainfall data was arranged monthly and using the DrinC software, the SPI time series were scaled for 3,6 and 12 months, and the values were calculated. Based on 
Table S3 (Different drought and drought classes in this index), using the values obtained from SPI between 2 and $+2,-2$ or less, $2+$ or more, periods of drought and the severity of drought was obtained in the classes of normal, mild, moderate, severe and very severe.

In this method, the drought period begins when the SPI is continuously negative to reach 1 or less, and ends when the SPI is positive. In addition, the cumulative amounts of SPI also show the magnitude and severity of the drought period. The positive SPI value represents the precipitation over the average rainfall and the negative value is the opposite. Therefore, the standard SPI index is suitable for dry and humid climates, and it is possible to compare results in different time periods and locations. In the following, maximum and minimum maximum and minimum values of SPI in the 3, 6 , and 12-month scales in the statistical period of the study are presented in Ta- ble 3 and 4, respectively. Finally, the results have been discussed. Also, spatial distribution of drought condition based on 12-month SPI in a number of study years is provided alternately in Table 2 . At this stage, after calculating the values of the SPI index, the most important features of dry and wet periods, including the total number of dry and wet months, in different classes of drought indicate that the results are presented in Table 3 to 5 .

\section{Results}

In this study, in order to analyze the effect of dry spells on drought, the SPI method is used. Because this is the common and the best method that can show the effect.

At this stage, for the drought assessment, the SPI index is created for the 39 years (1980-2019) and precipitation from 9 rain-gauge stations were calculated for DrinC software, and the values are shown in Table 3. The SPI index

Table 1. The characteristics of wet and dry condition in dry spells at 3 months

\begin{tabular}{|c|c|c|c|c|c|c|c|c|c|c|}
\hline & condition & $\begin{array}{l}\text { Station } \\
\text { 1(Dohuk) }\end{array}$ & $\begin{array}{l}\text { Station } \\
\text { 2(Arbil) }\end{array}$ & $\begin{array}{l}\text { Station } \\
\text { 3(Sinjar) }\end{array}$ & $\begin{array}{c}\text { Station } \\
4(\text { Tel affar })\end{array}$ & $\begin{array}{c}\text { Station } \\
5(\text { Dokan })\end{array}$ & $\begin{array}{c}\text { Station } \\
\text { 6(Derbandghan) }\end{array}$ & $\begin{array}{c}\text { Station } \\
7 \text { (Suleimaniyah) }\end{array}$ & $\begin{array}{l}\text { Station } \\
\text { 8(Mosul) }\end{array}$ & $\begin{array}{l}\text { Station } 9 \\
\text { (Kirkuk) }\end{array}$ \\
\hline & Max & 1.6 & 2.2 & 1.9 & 1.6 & 2.1 & 1.9 & 2.3 & 1.6 & 2 \\
\hline & Min & -2.1 & -2 & -1.5 & -2.4 & -1.7 & -2.1 & -2.4 & -2.1 & -3.04 \\
\hline & Moderate & 0 & 0 & 0 & 0 & 0 & 0 & 0 & 0 & 0 \\
\hline & $\begin{array}{l}\text { The number of months } \\
\text { with dry condition }\end{array}$ & 16 & 28 & 15 & 29 & 12 & 16 & 28 & 16 & 24 \\
\hline & $\begin{array}{l}\text { The number of months } \\
\text { with wet condition }\end{array}$ & 16 & 28 & 17 & 23 & 20 & 16 & 28 & 16 & 24 \\
\hline & $\begin{array}{c}\text { The number of months } \\
\text { with very severe wet } \\
\text { condition }\end{array}$ & 0 & 1 & 0 & 0 & 1 & 0 & 1 & 0 & 1 \\
\hline $\begin{array}{l}3 \text { months } \\
\text { dry spells }\end{array}$ & $\begin{array}{c}\text { The number of months } \\
\text { with severe wet } \\
\text { condition }\end{array}$ & 4 & 4 & 4 & 1 & 1 & 2 & 3 & 2 & 2 \\
\hline & $\begin{array}{c}\text { The number of months } \\
\text { with moderate wet } \\
\text { condition }\end{array}$ & 5 & 4 & 2 & 9 & 5 & 3 & 5 & 3 & 5 \\
\hline & $\begin{array}{l}\text { The number of months } \\
\text { with normal condition }\end{array}$ & 39 & 38 & 21 & 32 & 21 & 22 & 37 & 23 & 36 \\
\hline & $\begin{array}{c}\text { The number of months } \\
\text { with very severe dry } \\
\text { condition }\end{array}$ & 6 & 6 & 3 & 7 & 1 & 1 & 6 & 1 & 2 \\
\hline & $\begin{array}{c}\text { The number of severe } \\
\text { dry condition }\end{array}$ & 0 & 3 & 2 & 1 & 3 & 3 & 3 & 2 & 0 \\
\hline & $\begin{array}{c}\text { The number of months } \\
\text { with moderate dry } \\
\text { condition }\end{array}$ & 2 & 0 & 0 & 2 & 0 & 17 & 1 & 1 & 2 \\
\hline
\end{tabular}


values were then input into DrinC software for each station at three, three, six, and 12-month time scales so that their spatial analysis could be provided. The results of the stations obtained are as shown in Table 1 to 3 . From the years studied, the results of calculations based on Table 3 to 5 show that at a 3-month time scale, a very severe drought with a minimum of -3.04 corresponds to the station 9 (Kirkuk).

Also at a 3-month time scale, extreme wet period (with the highest value of 2.28) is related to station 7(Suleimaniyah).

At 6 months time scale, the lowest value (-3.02) is related to station 8 (Mosul) and the highest value is related to station2 (Arbil), while at a time scale of 12 Month, the lowest value (-2.9) is related to the station 3 (Tel Affar) and the highest value (2.3) is related to station 2 (Arbil).

The average value for each of the three time scales is -0.04 .

As a result of SPI's ability, the most frequent 17-month high drought was due to the station 6 (Derbandghan) and the longest extremely severe wet period was 1 year. In this study, the SPI index has been used as one of the most suitable indicators in the analysis of past dry spells and wet spells. Since the study area is sufficiently extensive, monthly information is used in comparison with the annual data due to the improvement of drought management, as well as the choice of the method based on the same time space.

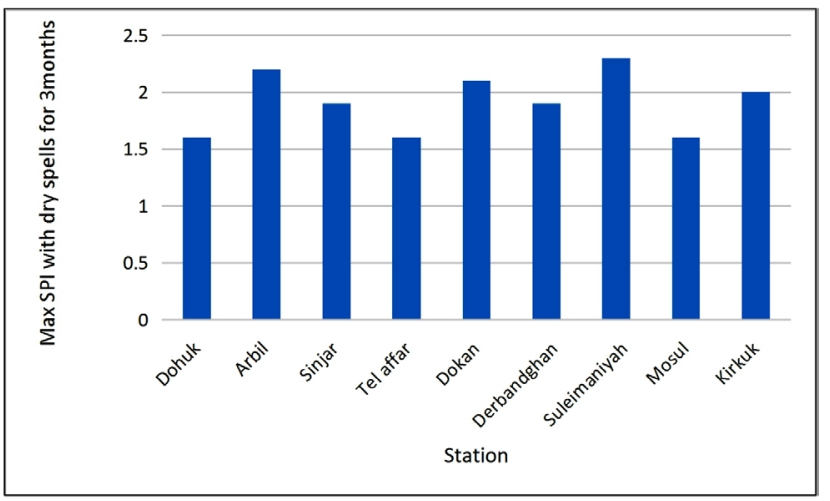

Figure 2. Max SPI with dry spells for 3 months .

Table 2. The characteristics of wet and dry condition in dry spells at 6 months

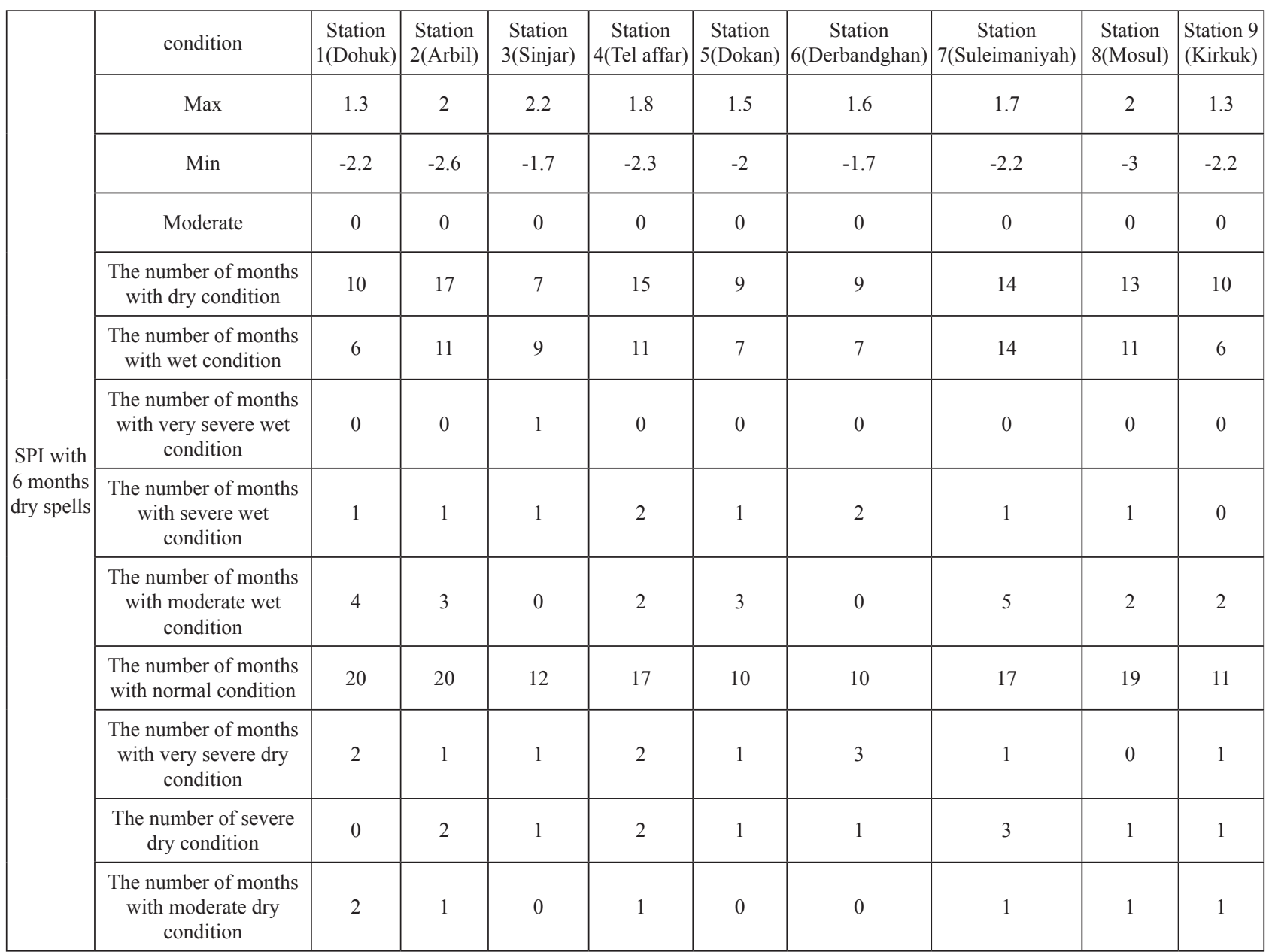




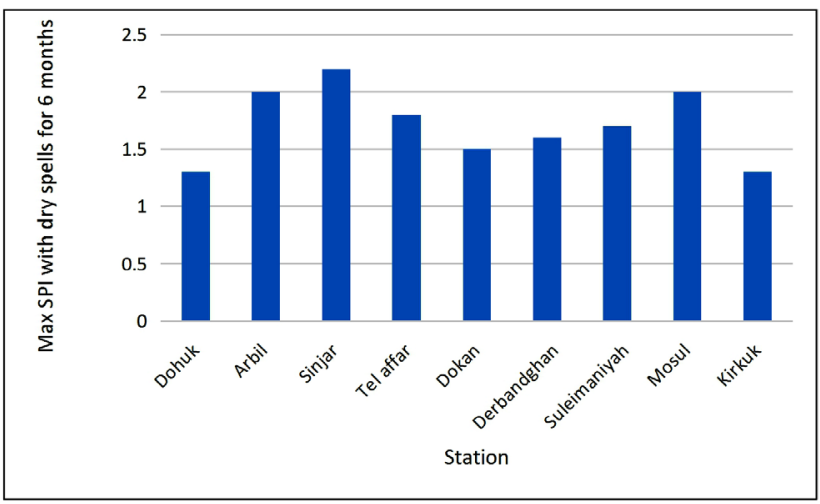

Figure 3. Max SPI with dry spells for 6 months.

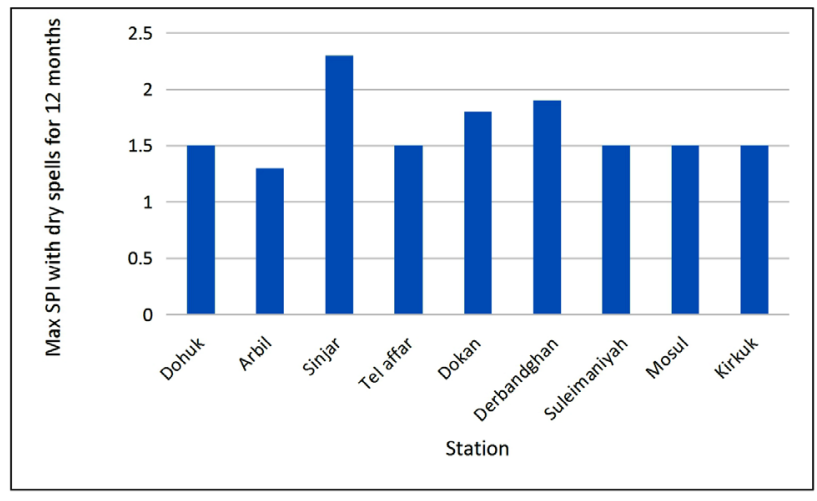

Figure 4. Max SPI with dry spells for 12 months.

Table 3. The characteristics of wet and dry condition in dry spells at 12 months

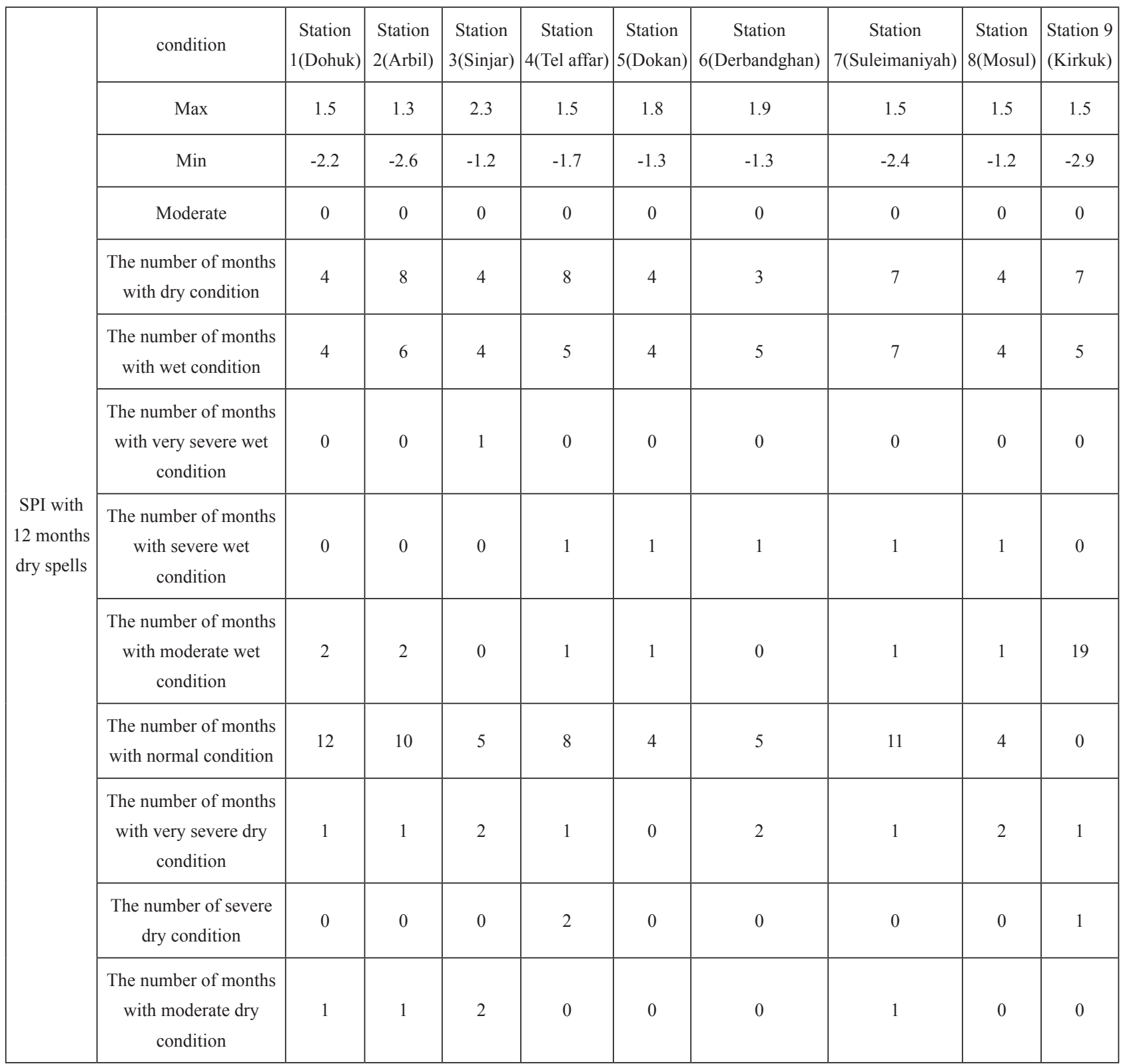




\section{Discussion}

From the review and analysis of the results of the research, the following general conclusions were drawn. Unlike previous studies (such as ${ }^{[40][41]}$ ) which only used a short period for analyzing dry spells, this study used a long period and all characteristics of dry spells (include intensity, duration) are analyzed in this study. In all 9 stations of the region, during the 39-year statistical period, wet and dry periods are observed and may be 2 or 3 consecutive wet seasons, followed by two or three successive droughts seasons or vice versa. In any of the nine stations surveyed, there was not just one precipitation situation in the past year. In other words, each year there should be expected different rainfall situations in different regions of the area. Based on the results, the standard rainfall indexes for each station in the area were classified into two periods of drought and wet, among which these values, the highest drought related to the station 9 and the smallest is related to station 2 and 3 due to its higher elevation from the sea surface and the snow in winter is higher, so moisture is higher than other parts of the area. The target index is the ability to monitor the occurrence, dry spells, and severity of each drought in different time periods. Also, with the normalization and standardization of the SPI index, it is possible to compare and categorize the severity of drought in a different time period, which is consistent with the results of ${ }^{[42],[43]}$, which used the benefits of the SPI index are in line with the drought classification and comparison. The use of this indicator to examine the trend of drought changes in the region showed that the trend of this phenomenon changes in different months of the year, not only at different points but also at different time scales, even for a specific station. Accordingly, station 9 has the first priority in terms of the severity of drought between the stations and station 2 has the last priority in terms of the severity of drought between the stations. Using indicators and recognizing the drought period by SPI method, is useful for providing proper environmental management plans and better management of dry courses, crisis management, risk management, agricultural insurance, and so on.

\section{Conclusions}

In order to analyze the conditions of the dry spells with using SPI method, the data from 9 meteorological stations for the year of 1980 to 2019 were used. The characteristics of dry spells and dry periods have been investigated. The characteristics of dry spells have been obtained by 3 classifications (drought conditions, mild conditions and normal conditions). The short-term and long term of dryspells have been discovered. The results showed that the highest consecutive of dry days and the maximum length of dry spells belongs to Derbandghan station. However, the lowest consecutive of dry days and the minimum length of dry spells belongs to Suleimaniyah station. The limitation of this study was data availability. So, for the future research based on the data availability other methods like SPEI and Markov chain can use for analyzing dry spells.

\section{Acknowledgment}

We thank Esfahan Regional Water Authority for funding this study to collect necessary data easily and helped the authors to collect the necessary data without payment, Mohammad Abdollahi and Hamid Zakeri for their helpful contributions to collect the data. All other sources of funding for the research collected from authors. We thank Omid Boyerhassani who provided professional services for check the grammar of this paper.

\section{References}

[1] Abdollahi, S., Javadinejad, S., Ostad-Ali-Askari, K., Vijay P Singh.,2019. Investigating the Effects of Landfill in Azad-Shahr City on the Physicochemical Properties of Groundwater. American Journal of Engineering and Applied Sciences, 12 (2): 136-146

[2] Agha, O.M.A.M., Bağçacı, S.Ç. and Şarlak, N., 2017. Homogeneity analysis of precipitation series in North Iraq. IOSR Journal of Applied Geology and Geophysics, 5(03):57-63.

[3] Al-Dabbas, M. A., Kreamer, D. K., Al-Shammari, A. A., \& Jwad, A. M. (2020). Management of bai hassan unconfined aquifer, lesser zab river basin, kurdistan region, iraq using a modeling approach. Iraqi Geological Journal, 53 (2): 1-23.

[4] Athukorala, W., Martin, W., Wilson, C., \& Rajapaksa, D. 2019. Valuing bushfire risk to homeowners: Hedonic property values study in Queensland, Australia. Economic Analysis and Policy, 63(1):44-56.

[5] Belayneh, A., Adamowski, J., \& Khalil, B. 2016. Short-term SPI drought forecasting in the Awash River Basin in Ethiopia using wavelet transforms and machine learning methods. Sustainable Water Resources Management, 2(1):87-101.

[6] Boudad, B., Sahbi, H., \& Mansouri, I. 2018. Analysis of meteorological and hydrological drought based in SPI and SDI index in the Inaouen Basin (Northern Morocco). J Mater Environ Sci, 9(1): 219-227.

[7] Feng, S. and Fu, Q., 2013. Expansion of global drylands under a warming climate. Atmospheric Chemistry and Physics, 13(19), pp.10081-10094.

[8] Hadi, S. H., \& Alwan, H. H. (2020). Surface wa- 
ter-groundwater interaction in diwaniya, southern iraq using isotopic and chemical techniques. Iraqi Geological Journal, 53(2):89-112.

[9] Javadinejad, S., Dara, R. and Jafary, F., (2020 ) Climate Change Scenarios and Effects on Snow-Melt Runoff. Civil Engineering Journal, 6(9): 1715-1725.

[10] Javadinejad, S., Dara, R. and Jafary, F., 2020. Potential impact of climate change on temperature and humidity related human health effects during extreme condition. Safety in Extreme Environments, 2(2), pp.189-195.

[11] Javadinejad, S., Mariwan, R. D. M. H. H., Hamah, A., \& Jafary, S. F. (2020). Analysis of Gray Water Recycling by Reuse of Industrial Waste Water for Agricultural and Irrigation Purposes. Journal of Geographical Research| Volume, 3(02).

[12] Javadinejad, S., Hannah, D., Ostad-Ali-Askari, K., Krause, S., Zalewski, M. and Boogaard, F., (2019). The impact of future climate change and human activities on hydro-climatological drought, analysis and projections: using CMIP5 climate model simulations. Water Conservation Science and Engineering, 4(2-3), 71-88.

[13] Javadinejad, S., Ostad-Ali-Askari, K., Singh, V.P. and Shayannejad, M., (2019). Reliable, Resilient, and Sustainable Water Management in Different Water Use Sectors. Water Conservation Science and Engineering, 4(2-3):133-148.

[14] Javadinejad, S., Eslamian, S., Ostad-Ali-Askari, K., Nekooei, M., Azam, N., Talebmorad, H., Hasantabar-Amiri, A. and Mousavi, M., (2019). Relationship Between Climate Change, Natural Disaster, and Resilience in Rural and Urban Societiesp:1-25.

[15] Javadinejad, S., Dara, R. and Jafary, F., 2019. Taking Urgent Actions to Combat Climate Change Impacts. Annals of Geographical Studies, 2(4): 1-13.

[16] Javadinejad, S., Ostad-Ali-Askari, K. and Eslamian, S., 2019. Application of Multi-Index Decision Analysis to Management Scenarios Considering Climate Change Prediction in the Zayandeh Rud River Basin. Water Conservation Science and Engineering, 4(1): 53-70.

[17] Javadinejad, S., Eslamian, S., Ostad-Ali-Askari, (2018). The Analysis of the Most Important Climatic Parameters Affecting Performance of Crop Variability in a Changing Climate. International journal of hydrology science and technology.

[18] Javadinejad, S., (2016). Vulnerability of water resources to climate change and human impact: scenario analysis of the Zayandeh Rud river basin in Iran (Doctoral dissertation, University of Birmingham).

[19] Javadinejad, S. and Jafary, R.D.F., 2020. Gray Wa- ter Measurement and Feasibility of Retrieval Using Innova-tive Technology and Application in Water Resources Management in Isfahan-Iran. Journal of Geographical Research, 3(02):11-19.

[20] Javadinejad, S. and Jafary, R.D.F., 2019. Effect of Precipitation Characteristics on Spatial and Temporal Variations of Landslide in Kermanshah Province in Iran. Journal of Geographical Research| Volume, 2(04):7-14.

[21] Javadinejad, S., Dara, R. and Jafary, F., 2020. Health impacts of extreme events. Safety in Extreme Environments, 2(2), pp.171-181.

[22] Javadinejad, S., Eslamian, S. and Ostad-Ali-Askari, K., 2019. Investigation of monthly and seasonal changes of methane gas with respect to climate change using satellite data. Applied Water Science, 9(8): 180 .

[23] Javadinejad, S., Dara, R. and Jafary, F., 2019. Impacts of Extreme Events on Water Availability. Annals of Geographical Studies, 2(3), pp.16-24.

[24] Javadinejad, S., Ostad-Ali-Askari, K. and Jafary, F., 2019. Using simulation model to determine the regulation and to optimize the quantity of chlorine injection in water distribution networks. Modeling Earth Systems and Environment, 5(3):1015-1023.

[25] Javadinejad, S., 2011. The 2008 Morpeth Flood: Continuous Simulation Model for the Wansbeck Catchment. Ebook, Grin publication.

[26] Javadinejad, S., Eslamian S., Ostad-Ali-Askari K., Mirramazani S.M., Zadeh L.A., Samimi M. (2018) Embankments. In: Bobrowsky P., Marker B. (eds) Encyclopedia of Engineering Geology. Encyclopedia of Earth Sciences Series. Springer, Cham. https://doi. org/10.1007/978-3-319-12127-7_105-1.

[27] Javadinejad, S., Dara, R., \& Jafary, F. (2019). Impacts of Extreme Events on Water Availability. Annals of Geographical Studies, 2(3), 16-24.

[28] Javadinejad, S., Dara, R. and Jafary, F., (2020). Analysis and prioritization the effective factors on increasing farmers resilience under climate change and drought, Agricultural research, DOI:10.1007/s40003-020-00516-w.

[29] Javadinejad, S., Dara, R. and Jafary, F., 2020. Evaluation of hydro-meteorological drought indices for characterizing historical and future droughts and their impact on groundwater. Resources Environment and Information Engineering, 2(1), pp.71-83.

[30] Mirramazani, S. M., Javadinejad, S., Eslamian, S., \& Ostad-Ali-Askari, K.,(2019). THE ORIGIN OF RIVER SEDIMENTS, THE ASSOCIATED DUST AND CLIMATE CHANGE, 8(2): 149-172.

[31] Mirramazani, S.M., Javadinejad, S., Eslamian,S., 
Jafary, F., Vijay P. Singh, Ostad-Ali-Askari, K.,2019. A Feasibility Study of Urban Green Space Design in the Form of Smart Arid Landscaping with Rainwater Harvesting, American Journal of Engineering and Applied Sciences,

DOI: 0.3844/ajeassp.201.1-9.

[32] Javadinejad, S., Dara, R. and Jafary, F., 2020. Analysis and prioritization the effective factors on increasing farmers resilience under climate change and drought. Agricultural research, pp.1-17.

[33] Javadinejad, S., Dara, R. and Jafary, F., 2020. Modelling groundwater level fluctuation in an Indian coastal aquifer. Water SA, 46(4), pp.665-671.

[34] Javadinejad, S., Dara, R. and Jafary, F.,2020. Investigation of the effect of climate change on heat waves. Resources Environment and Information Engineering, 2(1), pp.54-60. Available at: http://dx.doi. org/10.25082/reie.2020.01.001.

[35] Javadinejad, S., Dara, R. and Jafary, F.,2020. Examining the association between dust and sediment and evaluating the impact of climate change on dust and providing adaptation. Resources Environment and Information Engineering, 2(1), pp.61-70. Available at: http://dx.doi.org/10.25082/reie.2020.01.002.

[36] Javadinejad, S., Dara R, Jafary F, Dolatabadi N. Climate change management strategies to handle and cope with extreme weather and climate events. Journal of Geographical Research [Internet]. Bilingual Publishing Co.; 2020 Sep 30;3(4). Available from: http://dx.doi.org/10.30564/jgr.v3i4.2324.

[37] Javadinejad, S., Dara, R. and Jafary, F., 2020. How groundwater level can predict under the effect of climate change by using artificial neural networks of NARX. Resources Environment and Information Engineering, 2(1), pp.90-99.

[38] Javadinejad, S., Hannah, D.H., Krause, S.K., Dara, R., Jafary, F. and Naseri, M., 2020. THE IMPACTS OF CLIMATE CHANGE ON ENERGY-WATER SYSTEMS AND ECONOMIC ANALYSIS. The Iraqi Geological Journal, pp.1-17.

[39] Javadinejad, S., Hannah, D., Krause, S., Naseri, M., Dara, R. and Jafary, F., 2021. Building socio-hydrological resilience "improving capacity for building a socio hydrological system resilience". Safety in Extreme Environments, pp.1-14.

[40] Javadinejad, S, Dara R, Jafary F, Dolatabadi N. A Review on Homogeneity across Hydrological Regions. Biogeneric Science and Research. 2021 Feb 30;7(4). Available from: https://biogenericpublishers.com/ pdf/JBGSR.MS.ID.00173.pdf.

[41] Javadinejad, S, Dara R, Jafary F, Dolatabadi N. Modeling the Effects of Climate Change on Probability of Maximum Rainfall and On Variations in Storm Water in the Zayandeh Rud River. Biogeneric Science and Research.2021 Feb 30;7(4). Available from: https:// biogenericpublishers.com/pdf/JBGSR.MS.ID.00174. pdf.

[42] Dara, R.N., Jirjees, S., Fatah, K.K. and Javadinejad, S., 2021. Climatic Parameters Analysis of Koysinjaq Meteorological Station, Kurdistan Region, Northern Iraq. The Iraqi Geological Journal, pp.99-109.

[43] Jones, J.A.A. (2014) Global Hydrology: Processes, Resources and Environmental Management, Taylor \& Francis publication, Routledge. 